M. Kappler

Türkischsprachige Liebeslyrik in griechisch-osmanischen

Liedanthologien des 19. Jahrhunderts 
STUDIEN ZUR SPRACHE, GESCHICHTE UND KULTUR DER TÜRKVÖLKER

BAND 3

herausgegeben

von

György Hazai

KLAUS SCHWARZ VERLAG - BERLIN 
STUDIEN ZUR SPRACHE, GESCHICHTE UND KULTUR DER TÜRKVÖLKER

BAND 3

\section{Matthias Kappler}

Türkischsprachige Liebeslyrik in griechisch-osmanischen

Liedanthologien

des 19. Jahrhunderts 
Bibliografische Information Der Deutschen Bibliothek

Die Deutsche Bibliothek verzeichnet diese Publikation in der Deutschen Nationalbibliografie; detaillierte bibliografische Daten sind im Internet über http://dnb.ddb.de abrufbar.

Alle Rechte vorbehalten.

Ohne ausdrückliche Genehmigung des Verlages

ist es nicht gestattet, das Werk oder einzelne Teile daraus

nachzudrucken oder zu vervielfältigen.

(c) Gerd Winkelhane, Derlin 2002

Klaus Schwarz Verlag GmBH, Postfach 4102 40, D-12112 Berlin

ISBN 3-87997-302-4

Druck: Akaprint, Budapest

ISBN 3-87997-302-4 